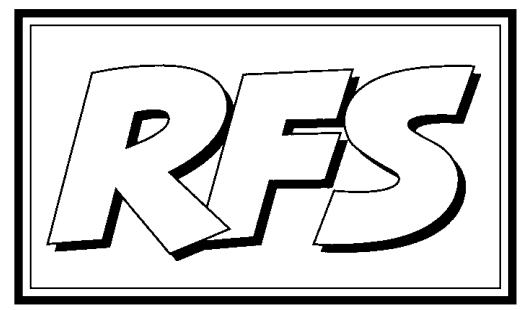

Revista de Fomento Social, 55 (2000), 143-160

\title{
Globalización integradora vs. globalización excluyente
}

Consejo de Redacción

La globalización suscita las reacciones más encontradas. Con nada que se haya reflexionado sobre ella ( $i a$ veces sin haber reflexionado en absoluto?) se toma postura a favor o en contra. Se la canoniza o se la demoniza. Y siempre, con una fuerte dosis de simplificación. Por eso el debate es difícil: en él es casi imposible acercar posturas.

Este debate es el que queremos dejar reflejado en las páginas que siguen. Naturalmente, tomaremos, también nosotros, postura. Pero, antes de hacerlo, procuraremos analizar los distintos aspectos del tema, clarificar el concepto mismo de globalización, examinar las posiciones desde las que se aborda.

Es inevitable comenzar examinando los hechos: ese fenómeno multidimensional que, nos guste o no, nos envuelve, por muchos matices que queramos introducir. Facilidad de desplazamientos físicos, comunicaciones fluidas a todos los niveles, una cultura cada vez más estandarizada, movimientos de capitales, acceso a productos de las más lejanas latitudes... Todo eso, que lo estamos viviendo cada día, impone un estilo a nuestra vida y se nos presenta como un cúmulo de oportunidades, aunque a veces no deje de provocarnos 
malestar e incomodidad. ¿Es posible encontrar una interpretación y llegar a una valoración de todo eso?

\section{Empezar por una aproximación conceptual}

Dirigirse al Diccionario de la Real Academia Española no nos aporta mucha luz. En la edición 21, de 1992, ni siquiera figuran los términos globalización o mundialización.

Sí aparecen otros términos, que tienen cierta relación. Citamos dos. Integración se define como "incorporación, unión a un grupo para formar parte de él"1. Internacionalización es "sometimiento a la autoridad conjunta de varias naciones, o de un organismo que las represente, de territorios o asuntos que dependían de la autoridad de un solo Estado". En ambos términos (sobre todo en internacionalización) se aprecia claramente la contraposición nacional/ supranacional: subrayamos este detalle porque tiene que ver con uno de los rasgos distintivos de la globalización.

Otro aspecto a retener en torno al concepto de globalización y otros cercanos es la dimensión económica. En este sentido, el término internacionalización es usa do frecuentemente en el contexto del GATT para designar el "conjunto de los intercambios de materias primas, de productos semielaborados y elaborados, de servicios, de dinero, de ideas y de personas que se realizan entre estas entidades estadísticas que son los países". Próximo a él, la multinacionalización se define como "La transferencia y la deslocalización de recursos, sobre todo del capital y, en una menor medida, de la mano de obra, de una economía nacional a otra".

Estamos, pues, ante dos conceptos próximos (internacionalización y multinacionalización). Ambos subrayan la contraposición nacional/ supranacional; y suelen emplearse además con una insistente connotación económica para referirse a los intercambios de recursos (base del comercio internacional) o a la transferencia/ deslocalización de los mismos ( gracias a las técnicas y teorías sobre la gestión).

1 Valga, como primera aproximación, esta definición tan general, pero la palabra integración ha adquirido contenidos más ricos cuando se refiere a procesos de agrupación de países; es más, con el mismo término se designan niveles de integración muy distintos, que merecen valoraciones diferentes también. 


\section{De las definiciones neutras a los debates sobre la interpretación de los conceptos}

Es indudable que todas estas consideraciones hechas a partir del diccionario no nos aportan excesiva luz para comprender el fenómeno de la globalización. Indagaremos ahora un camino diferente: el de las distintas interpretaciones que se han dado de él. Es fácil detectar que existen dos grandes corrientes interpretativas, que provienen respectivamente del mundo anglosajón y del europeo continental.

La posición anglosajona subraya que la globalización es, ante todo, un hecho, una realidad que se nos impone, independientemente de que nos sintamos cómodos o incómodos con ella. Así lo expresa Thomas L. Friedman, que entiende la globalización como el sistema que impera tras la "guerra fría", al que sustituye. Globalización y guerra fría son dos sistemas antagónicos, el primero caracterizado por la "integración", el segundo por la "división". El símbolo más acabado de este último es el "muro de Berlín"; el de la globalización, la "red mundial".

Pero la globalización es una realidad, no sólo político-estratégica, sino también cultural. Se manifiesta como una "cultura dominante", marcada por los estándares americanos (sus valores, símbolos e imágenes), que se difunde incontenible por todo el planeta gracias a su capacidad integradora y tiende a ser homogeneizadora, es decir, a imponerse como cultura única a nivel mundial.

Frente a esta postura, que subraya más lo fáctico, otros autores -entre ellos, los franceses IGNACIO RAMONET y AlaIN TOURAINE- interpretan la globalización ante todo como una ideología, a la que relacionan con el pensamiento neoliberal. Quieren encontrar sus orígenes en Bretton Woods (1944) y en las estructuras mundiales que allí se engendraron, sobre todo económicas y monetarias, de las que el Fondo Monetario Internacional y el Banco Mundial son las más sobresalientes.

Es cierto que ha llovido mucho en este medio siglo que nos separa del final de la segunda guerra mundial. Pero en este período las instituciones entonces creadas no han hecho sino consolidarse y multiplicarse, promoviendo unas relaciones económicas entre los países cada vez más fluidas y fortaleciendo la interdependencia recíproca, para ir configurando así un sistema económico mundial crecientemente unificado. Sus bases son una economía de mercado de dimensiones cada vez más planetarias (mercado mundial único), favorecida 
por los espectaculares avances en los sistemas de comunicación. Estamos, entonces, ante un verdadero "nuevo orden global", cuyo eje vertebrador es un principio fundamental: que "lo económico prevalece sobre lo político".

El pensamiento neoliberal, que esta segunda corriente interpretativa identifica con el llamado pensamiento único, sirve como factor legitimador de este sistema globalizado, al que dota de estabilidad. La denominación de pensamiento único alude a la pretensión de presentarse con una fuerza de evidencia que elimina en la práctica la posibilidad de alternativas.

Este nuevo orden global no sería sólo una realidad fáctica, sino además un verdadero "proyecto estratégico global". En efecto, en él se mezclan lo fáctico y lo estratégico, como se puede comprobar en los elementos que suelen señalarse como característicos del mismo:

1) Se está configurando un nuevo marco político, donde las soberanías nacionales clásicas (los Estados-nación) van cediendo en favor de otras soberanías menos definidas: unas son de carácter supranacional (derivadas de procesos de integración regional o del fortalecimiento de los organismos internacionales), mientras que otras son de carácter transnacional. Este último es el caso de la empresas multinacionales, nuevos sujetos de poder a escala mundial, que escapan cada vez más al control de los Estados (cuando no se valen de ellos como instrumentos para sus fines económicos) y se han desarrollado espectacularmente bajo el impulso de una doble lógica: la reducción de los costes y la replicación basada en la concesión de franquicias.

2) Pero las grandes potencias mundiales no se resignan a perder poder y buscan mantenerlo mediante estrategias nuevas, basadas en el fortalecimiento del poder militar, que han surgido tras la caída del muro de Berlín. Entre ellas cabe citar la sustitución progresiva y fáctica de la ONU por la OTAN, y de la OTAN por los Estados Unidos.

3) Este poder, que no es menor que el de otros tiempos, sí actúa de forma muy diferente. Ha hecho casi desa parecer las guerras clásicas de agresión y las va sustituyendo por guerras punitivas, de castigo ( cero muertos, catástrofes ecológicas, guerra invisible con manipulación de los media), cuyo objetivo es la eliminación de las turbulencias (socio-económicas, políticas, étnicas, religiosas, etc.) y, en último término, incluso de los países que las generan (casos del Magreb, los Balcanes, el Oriente Medio, etc.).

Estos últimos datos nos ayudan a descubrir una dimensión más honda que se 
oculta tras la globalización: la lucha por la hegemonía en el mundo. Si Estados Unidos es el país que más abiertamente lo manifiesta y el que mejores medios tiene para ello gracias a su poder militar inigualable (recuérdense sus "éxitos" más recientes en la Guerra del Golfo y en el conflicto de Kosovo), no es menos cierto que encuentra siempre una fuerte resistencia de parte de otras grandes potencias. Esta lucha por la hegemonía es decisiva para comprender todo el proyecto europeo.

\section{Un nuevo intento de clarificación conceptual}

Si no queremos ahondar en el antagonismo geográfico, por miedo a caer en ciertas simplificaciones, retengamos al menos dos contraposiciones que derivan de la exposición que precede porque nos ayudarán a concretar más el sentido de la globalización.

La primera de estas contraposiciones se refiere a la alternativa entre continuidad y ruptura. Touraine lo ha expresado distinguiendo los conceptos de globalización y mundialización. La mundialización subraya la continuidad: el elemento continuador de las tendencias aperturistas, que se aceleran en la segunda mitad del siglo XX hasta abarcar, no sólo lo económico (que es la globalización propiamente dicha), sino progresivamente lo cultural, lo político, lo social, lo cosmovisional y hasta lo religioso. La globalización se centra en la dimensión económica, que termina imponiendo su ley: sería un proceso de verdadera ruptura con el pasado, un proceso que ha llevado a los pueblos a ceder el poder sobre sus economías y sus sociedades a fuerzas globales y no democráticas, tales como los mercados, las agencias de calificación de deuda, etc.

Nosotros optamos por esta segunda porque así nos parece que se capta mejor el alcance del fenómeno que estamos estudiando. En este sentido, la globalización es el proceso a través del cual se está consolidando, con la ayuda inestimable de los principios del liberalismo, el espacio único mundial, no sólo como el escenario en el que se da la vida de todas las poblaciones del planeta, sino como el referente inevitable de to das las actividades productivas, financieras, políticas, sociales y hasta culturales para cualquier toma de decisión. Estado, nación, mercado nacional, identidad nacional tienen cada vez menos fuerza como marco de referencia: todos estos ámbitos quedan desbordados por el mercado mundial y la cultura globalizada.

El Grupo de LisBoA ha subrayado, certeramente en nuestra opinión, el alcance 
de esta ruptura destacando cómo la globalización ha minado uno de los rasgos que se mantenían en la historia moderna, a pesar de la creciente interdependencia: el predominio de dinámicas de carácter nacional. En efecto, el Estado nacional seguía siendo la forma última de organización política y social; la identidad nacional determinaba la existencia y la personalidad de los individuos y de los grupos sociales; la historia nacional (lengua, cultura, sistema educativo, red ferroviaria, equipos deportivos) no dejaba de ser el núcleo en torno al que la sociedad se construía. Pero la globalización ha comenzado por cuestionar una de las bases principales del Estado-nación: el mercado nacional. Esto significa que, desde el punto de vista estratégico, el espacio económico por excelencia ha pasado a ser el espacio mundial. La globalización acarrea, entonces, la superación de lo nacional y de lo estatal, para ser deglutidos por el sistema único y el mercado global. ¿No es esto suficiente para hablar de una auténtica ruptura?

Pero hay una segunda contraposición que es aún más evidente en las dos corrientes antes reseñadas: la contraposición entre la globalización entendida como hecho y entendida como ideal o como proyecto. La realidad de la globalización es un hecho incontrovertible, pero eso no obsta para hacer una valoración de ella. Si la interpretamos como algo beneficioso sin matices, sería lógico apostar por ella sin condiciones. Y esto nos resulta mucho más discutible. Pero con esto estamos ya adentrándonos en el juicio ético sobre ella. Y, efectivamente, será de aquí de donde arrancará más abajo nuestra crítica de la globalización. Pero antes queremos abundar algo más en los aspectos descriptivos.

\section{Globalización y mercado único}

La unificación del mercado mundial es probablemente el rasgo más característico de la globalización. Ya hemos explicado cómo a la fragmentación tradicional de los mercados, sometidos cada uno al control de su propio Estado, ha sucedido una progresiva y generalizada eliminación de los controles en frontera, y de las fronteras mismas. Veamos más en concreto los niveles a que se desarrolla esta unificación mundial del mercado:

19) Las mercancías. Aunque el comercio de materias primas y de productos elaborados es un fenómeno antiguo y ha sido una característica constante de la producción capitalista, la realidad es que en las últimas décadas el volumen del comercio mundial ha crecido enormemente, a mayor 
ritmo que la misma producción. Es cierto que este comercio es mucho más intenso entre los países desarrollados, pero también es evidente que las exportaciones de algunos países atrasados (los países de nueva industrialización) han inundado los mercados internacionales. El viejo esquema de exportaciones del materias primas desde el tercer mundo a cambio de importaciones de productos manufacturados procedentes de los países industrializados, ya no refleja exactamente la realidad: porque hoy el llamado tercer mundo ya no es mero importador de mercancías producidas por la industria de los países avanzados.

2) El capital productivo (inversión directa). Desde la segunda guerra mundial las empresas multinacionales se han ido extendiendo por todo el mundo, pero ha sido en las dosúltimas décadas cuando se ha acelerado la globalización de la inversión directa. Además, el fenómeno de las empresas multinacionales ha dejado de ser algo exclusivo de Estados Unidos: ahora son empresas de todos los países avanzados, incluida España, las que invierten en todo el mundo. La expansión de las empresas españolas por América Latina, de la que continuamente hablan los medios de comunicación, confirma esta movilidad del capital productivo, que apenas conoce ya restricciones en frontera. Pero tampoco cabe ignorar aquí que los flujos de inversión directa no se reparten por igual por todas las regiones del globo.

3o) El capital financiero (valores de renta fija y variable). Este es sin duda en caso en que la unificación mundial del mercado adquiere un ritmo de avance más meteórico. A esta globalización de los mercados internacionales de capital ha contribuido la liberalización de los mercados financieros, respondiendo a la fuerte demanda de recursos financieros en grandes cantidades por parte de las empresas multinacionales, los gobiernos y los organismos internacionales. El nacimiento del mercado de eurodólares en los años sesenta y la creación en Europa de la Unión Económica y Monetaria han profundizado este proceso. Pero a esta demanda procedente de la economía real se une cada vez con másfuerza la demanda de fondos con carácter exclusivamente especulativo. El carácter casi instantáneo de estas operaciones, gracias a los adelantos tecnológicos e informáticos, es otro rasgo típico de la nueva situación, que hace aún más atractivas las actividades especulativas.

4) La fuerza de trabajo. Los movimientos migratorios son tan antiguos como la humanidad, pero su importancia reciente no tiene equivalente en el 
pasado. Aunque sometidos todavía a restricciones notables, para evitar los desplazamientos masivos e incontrolados, estos movimientos desde los países menos desarrollados hacia el mundo más adelantado (Estados Unidos y Unión Europea) están creando si tuaciones inéditas, que obligan a hablar de sociedades multirraciales y multiculturales. Este encuentro de personas de diferentes países, culturas y religiones, cuyo motivo último es, en muchos casos, la lucha por la supervivencia, no siempre transcurre pacíficamente. Los brotes de racismo y de xenofobia no son extraños, como han puesto de relieve los recientes acontecimientos de EI Ejido (Almería), y muestran que estamos muy lejos, no ya de una verdadera interculturalidad, sino incluso de una multiculturalidad basada sólo en el respeto elemental del "otro".

Este mercado unificado se manifiesta en casi todos los sectores económicos con características semejantes:

a) Se globaliza el transporte, gracias a la expansión de la aviación y, en menor medida, de las líneas de alta velocidad, sin excluir el automóvil en espacios más reducidos. Las distancias se han acortado, el turismo y los viajes de negocios se han incrementado. Los movimientos migratorios están también influidos por estas facilidades del trasporte.

b) Se globalizan las comunicaciones, sobre todo las de tipo informático y electrónico, que posibilitan la fácil transmisión de noticias e informaciones. Las comunicaciones a través de Internet constituyen una de las novedades más importantes del siglo XX. No hay que olvidar, sin embargo, que el acceso a Internet no tiene el mismo desarrollo en todos los países $y$, por eso, es una nueva fuente de desigualdades, ahora en el terreno de la distribución del conocimiento.

c) Se globalizan las imágenes. Basta acercarse a los medios audiovisuales, al cine, a la industria del vídeo, y sobre todo a la televisión, para comprender hasta qué punto el mercado de imágenes ha alcanzado un carácter global. El caso más típico es el de la televisión por su alto porcentaje de contenidos que podríamos llamar internacionales, dada la presencia de algunas poderosas cadenas en casi todos los países.

d) Se globalizan los patrones de consumo. La generalización de los patrones de consumo, con origen casi siempre en productos "made in USA" ("macdonalización"), ha estandarizado las costumbres eliminando en gran parte las peculiaridades locales y haciendo cada vez más semejante 
el paisaje urbano de todos los países. En este sentido la globalización no tiene el mismo significado en todos los países: por un lado están los países que exportan sus patrones de consumo, sobre todo Estados Unidos, y por otro los que imitan esos patrones. Es una verdadera colonización cultural.

e) Y se globalizan, sobre todo, como ya hemos dicho, los mercados financieros. Este es el caso más típico de la globalización económica. Pero sus efectos no se circunscriben a la economía. Las actividades especulativas, que copan esos mercados financieros, imponen un modo de ser, una cultura económica, que prioriza la obtención del lucro, cuanto más rápido y más cuantioso mejor, independiente de sus efectos sobre la economía real de prosecución de bienes y servicios.

\section{Globalización y sistema económico único}

Este mercado unificado de múltiples manifestaciones se constituye en base de un único sistema económico. Este nuevo paso tiene que ver con el agotamiento de los modelos anteriores, el colectivismo y el Estado social del capitalismo mixto.

La caída de los regímenes colectivistas ha mostrado que una economía radicalmente intervenida desde el poder político carece de viabilidad y termina desmovilizando a la sociedad. Esto nadie osaría discutirlo hoy. Más cuestionable es la carrera incontenible de los países excomunistas hacia una economía de mercado sin restricciones. Los resultados, hasta donde podemos valorarlos hoy, no son esperanzadores.

Más problemática en su interpretación es la crisis del Estado social ${ }^{2}$. No cabe duda que este modelo generó en las décadas de su expansión un alto grado de bienestar económico y de estabilidad social. Pero es posible que el consenso acrítico en torno a él tenga que ver con la crisis que se presentó desde los años 80 , agravada por los cambios del contexto mundial. En todo caso, desencadenada la crisis, impresiona la virulencia de la ofensiva ideológica que se ha desatado contra él.

Si el Estado de bienestar europeo, tan orgulloso de sus indudables logros, ha resistido con dificultad a la crisis, ¿qué decir de otros modelos menos consoli-

2 Véase nuestro intento de valorarla en: Crisis y futuro del Estado de bienestar, Revista de Fomento Social, Córdoba, Publicaciones ETEA, no 198, 50 (1995) 149-169. 
dados (y menos avalados por los resultados), por ejemplo en el continente latinoamericano? En esos casos, la ofensiva ha encontrado realidades mucho más vulnerables...

La conclusión que parece imponerse de esta debacle es que se han acabado las alternativas. Y ese ha sido el mensaje difundido bajo la inspiración de un liberalismo rejuvenecido, tan expresivamente plasmado en el título que hizo conocido en todos los círculos intelectuales a Francis Fukuyama: El fin de la historia. Sólo el capitalismo, y precisamente en su versión más radical, es viable. Ni siquiera los modelos más sofisticados, o menos radicales, de capitalismo son defendibles. La frase tantas veces citada de Ronald Reagan sintetiza de forma apodíctica la conclusión: "El Estado no es la solución; el Estado es el problema" ${ }^{3}$.

Y si el capitalismo de mercado es el mejor sistema para la organización de cualquier economía, también lo es para estructurar la economía mundial. Aquí no hay que luchar contra el Estado que se arroga la función de velar por el buen funcionamiento de la economía, sino contra los Estados que se empeñan en defender sus propias economías del resto del mundo. El mensaje es el mismo: liberalizar. Pero ahora liberalizar significa eliminar las fronteras, facilitar la integración de todas las economías en ese único sistema mundial.

Llegados a este punto nos encontramos de lleno en un mundo globalizado, pero ahora la globalización tiene un claro sentido ideológi co-legitimador. Es un proyecto que merece concentrar todos los esfuerzos y servir de norte a todas las estrategias. Su objetivo general es la liberalización de los mercados para crear las condiciones de un relanzamiento sostenido del crecimiento económico, mediante la intensificación de la productividad, la competencia y la neutralidad. Este objetivo general se despliega en otros complementarios entre sí:

1) Apertura de los mercados. Es una condición necesaria para hacer rentables las grandes inversiones. Para ello es obligatoria la eliminación de las barreras comerciales. En esta línea la Ronda Uruguay y la creación de la Organización Mundial del Comercio (OMC) han promovido un mayor desmantelamiento arancelario. Pero, una vez más, la liberalización comercial y arancelaria ha sido selectiva, favoreciendo descarada-

3 El movimiento llamado de la "tercera vía" ha surgido recientemente como un intento de búsqueda de alternativas, aunque muy circunscrita a los países desarrollados. Véase nuestra valoración del mismo en: ¿Es posible la tercera vía?, Revista de Fomento Social, no 215, 54 (1999) 289-308. 
mente a los países industrializados. No se olvide una cifra: se ha estimado que el coste que suponen las trabas arancelarias impuestas por los países ricos a los productos de los países pobres equivalen a 14 veces la ayuda oficial al desarrollo que reciben estos últimos. El reciente fracaso de Seattle, del que se han congratulado no pocos, debe ser valorado con cautela: si va a ser el punto de partida para un giro en las negociaciones hacia planteamientos nuevos, hay que interpretarlo como un suceso esperanzador; pero si supone un freno a las negociaciones comerciales para que todo se quede como estaba, sus consecuencias podrían ser muy negativas para el tercer mundo.

2º) Reordenación de la división internacional del trabajo. En este sentido aparecen dos novedades importantes: la creación de materiales sintéticos y la revolución verde. Ello permite que los países adelantados pasen a ser oferentes de materias primas y de productos agrarios que antes tenían que importar de los países en desarrollo. La deslocalización de la producción industrial, que ha sido posible por las innovaciones tecnológicas y las facilidades para la movilidad del capital, ha permitido la aparición de los nuevos países industrializados. Pero todo esto ha traído consigo nuevas y mayores dificulta des para el acceso a los mercados de los demás países del tercer mundo.

3o) Reducción del papel de las administraciones públicas, como la forma de concretar el principio de "menos Estado", tantas veces repetido. Esta estrategia incluye varias vertientes:

* La privatización de las empresas públicas, que se presenta como un medio para aumentar la competitividad de los mercados e incrementar la productividad de las empresas. Los programas de privatización alcanzan en algunos casos a los servicios sociales y asistenciales relacionados con el Estado del bienestar.

* La reducción de la beligerancia en política fiscal, concretada en una menor presión fiscal. El equilibrio presupuestario, que se considera imprescindible, supone la reducción de la actividad pública, siempre en la línea del llamado "Estado mínimo".

* La desregulación de los mercados laborales para poder afrontar la competencia de los países de nueva industrialización y de otros países en los que la inexistencia de normas reguladoras permite el llamado "dumping social". 


\section{Reconstruyendo el árbol genealógico del pensamiento único}

Varias veces nos hemos referido a la dimensión ideológica de la globalización, y hemos aludido al Ilamado pensamiento único como su principal factor de legitimación. Es cierto que esta denominación no gusta a muchos autores, especialmente a los que son adscritos a dicha tendencia porque opinan que es grande el pluralismo de posiciones entre los que parten de una crítica radical del orden económico que entró en crisis en los años 70. Sin negar ciertas diferencias ulteriores, no parece superfluo recorrer brevemente este tronco común, a modo de "árbol genealógico". Ello nos permitirá también constatar que esta corriente de pensamiento no ha surgido de la noche a la mañana, sino que tiene precedentes en la tradición filosófica y científica de los dos últimos siglos, dignos de ser recordados.

Como antecedentes en los siglos XVIII y XIX habría que mencionar, por lo menos, el positivismo de Augusto Comte, el liberalismo económico de Adam Smith, el darwinismo de Charles Darwin y el darwinismo social de Herbert Spencer. Puntos comunes de estas corrientes podrían ser al menos dos: su acentuado individualismo, su concepción de la convivencia social como lucha donde para muchos la supervivencia se hace más que problemática.

Estos dos aspectos son los que alcanzan una difusión mundial en el siglo $X X$, al mismo tiempo que se radicalizan. El hombre unidimensional, de Herbert Marcuse, fue ya un toque de atención en los 60. La Escuela de Chicago ( los "Chicago boys") aplicaron aquellas ideas a la economía, a los que se unieron las universidades de Columbia, Harvard y Stanford. La realización política de estas nuevas ideas tuvo como pioneros a Ronald Reagan y a Margaret Thatcher, los primeros "neoliberales militantes". Desde los Estados Unidos y la Inglaterra de comienzos de los 80 las propuestas neoliberales se extienden de forma arrolladora por los cinco continentes. La crisis económica, que se había iniciado en los 70, las dificultades crecientes con que tropezaron los países que se aferraban con orgullo al Estado social, la caída espectacular de los regímenes colectivistas de Europa, el cambio de rumbo en la inmensa y misteriosa China, el fulgurante éxito de ciertas economías asiáticas, to do parecía a puntar en la misma dirección: la que Francis FuKUYAmA expresó con su tesis ya citada de El fin de la historia. Según él, la economía de mercado, unida al complemento indisociable de una democracia representativa, es ya el modelo único y definitivo, porque los hechos se han encargado de demostrarlo: sin alternativas, la historia ha llegado a su fin. "La aldea global" se encarga de dar cobertura social, con unas nunca soñadas 
facilidades de comunicación, a este sistema único y global.

No es incoherente este conjunto de hechos históricos, procesos y teorías. Y, al interpretar esos hechos y procesos, se ha ido construyendo una línea de pensamiento que, en su pretensión de explicar lo ocurrido de la forma más objetiva posible, ha elaborado una verdadera ideología, que conlleva una determinada visión de la persona y de la sociedad, un sistema de valores. Ese es el neoli beralismo, que recoge intuiciones procedentes de los grandes clásicos del pensamiento liberal, pero con matices claramente radicalizadores.

\section{Intento de valoración ética}

El camino recorrido hasta aquí nos permite ya abordar una toma de posición. Como ya dijimos, la distinción entre el hecho de la globalización y la ideología globalizadora es una base para un juicio crítico equilibrado y acorde con la complejidad del tema.

Por decirlo en pocas palabras: no podemos admitir que la globalización sea buena para todos y en todos sus extremos y manifestaciones. En ese sentido estamos contra todo intento, abierto o sola pado, de ideologización. Nos parece más a decuada la postura del PNUD, en su Informe sobre el desarrollo humano 1997, cuando afirmaba que "la globalización tiene ganadores y perdedores" $y$ exige, por consiguiente, ser gestionada ${ }^{4}$.

Que la globalización tiene ganadores y perdedores no extrañará a nadie. No sólo porque los datos lo confirman: de hecho, han aumentado las diferencias entre los países desarrollados y en desarrollo, y han aumentado también el desempleo y la desigualdad en los países industrializados. También porque esa es la tendencia del mercado siempre que actúa sin restricciones. Si la globalización es una apuesta por el mercado, de ella se deben seguir todas las ventajas y los inconvenientes que caracterizan a éste. Y sabemos que, siempre que las condiciones de partida de los que intervienen en el mercado son desiguales, la dinámica intrínseca a éste tiende a ahondar las diferencias. $\mathrm{Ni}$

4 En términos parecidos se ha expresado J. GARCíA RoCA, intentando interpretar la relación entre mundialización y globalización en términos dialécticos. La tesis sería la mundialización, en cuanto que amplía la conciencia de pertenencia al mismo mundo, suscitando el sentido de la solidaridad o el enfoque cooperativo entre la gente (el mundo como hogar). La antítesis sería la globalización, identificada con el capitalismo salvaje de dimensiones planetarias. La síntesis sería la necesidad de domesticar la globalización. 
siquiera las sociedades más avanzadas han conseguido librarse de este extremo en cuanto han comenzado a liberalizar sus economías, a pesar de que las condiciones de partida en ellas son menos desiguales y los instrumentos correctores más potentes. ¿Qué se puede esperar cuando las partes son tan heterogéneas como las grandes empresas multinacionales o las instituciones financieras frente a países con go biernos débiles, economías desestructuradas y mayorías empobrecidas? No podemos sorprendernos si, en el marco de la globalización reciente, la economía mundial crece pero, simultáneamente, se profundizan las desigualdades.

Más aún, hay que ser cautos cuando se habla de la globalización como un fenómeno universal. Porque la densificación del tejido comercial y financiero no afecta a todos por igual: las transacciones comerciales se concentran en determinadas áreas geográficas, y lo mismo ocurre con los movimientos de capital. Que mercancías y capitales puedan circular con gran libertad por todas las latitudes del globo, no implica automáticamente que lo hagan por todas partes con la misma intensidad. Son datos conocidos que la participación del África subsahariana en el comercio mundial no hace más que decrecer y que la inversión directa en el tercer mundo se concentra en un decena de países. La globalización es, por consiguiente, también excluyente.

\section{¿Cómo gestionar la globalización?}

Hemos insistido en los inconvenientes de la globalización. Pero tampoco queremos ignorar sus ventajas. Si no las tuviera no tendría sentido hablar de gestionarla, que es nuestra propuesta. Gestionarla es someterla a un control racional según criterios humanizadores, convertir lo que son oportunidades para unos pocos afortunados en oportunidades para todos.

A primera vista parecerá nuestra propuesta de gestionarla una propuesta sin sentido. $Y$, sin embargo, estamos convencidos que lo que sigue no es una manifestación de voluntarismo utópico. En realidad, nos apoyamos en propuestas que vemos surgir desde las plataformas más diversas. En un deseo de sistematización las concretaríamos en tres dimensiones:

1a) Un nuevo sistema de gobierno mundial. Si volvemos a la discusión sobre el mercado, nos vemos obligados a postular una instancia ajena a él que lo someta a control desde una lógica diferente. Esa instancia ha sido el Estado, siempre que se ha tratado de una economía particular. Cuando el problema se sitúa a nivel planetario, el disponer de una instancia reguladora se hace mucho 
más complicado. Pero es precisamente a este nivel donde están surgiendo las primeras propuestas. La más concreta es quizás la de someter a cierta regulación los mercados financieros, después de las experiencias funestas de la década de los 90 ( México, países asiáticos, Rusia, Brasil): esa regulación exige algún tipo de autoridad...

Si pasamos del caso concreto a la estructura general, la demanda de un sistema de gobierno mundial ( para el que ya se ha inventa do la palabra inglesa, governance, y la francesa, gouvernance) se abre paso con fuerza. Es importante comprender cómo se podría caminar hacia esta autoridad mundial, que no habría que concebir según el modelo del Estado, sino como una instancia supraestatal de alcance planetario. Tampoco se trata de pensar en algo que será realidad en un plazo breve de tiempo, pero sí en un proyecto a largo plazo, que será como el horizonte de las medidas que se vayan tomando desde ahora.

El punto de partida han de ser las instituciones existentes: la ONU y sus organismos especializados y también, por qué no, el FMI y el BM. No hay que pensar en sustituirlas, sino en reforzarlas, reactivando todas sus posibilidades y potenciando su autonomía con el beneplácito de los gobiernos y la renuncia de éstos a ejercer su poder sobre ellas. Además, para que estas instituciones ganen en credibilidad, de la que tan faltas están, es preciso que aumente su transparencia y su neutralidad: en una palabra, que sean verdaderamente democráticas. Así se irá construyendo un sistema de gobierno mundial desde la partici pación de todos los go biernos y de toda la sociedad civil, lejos del modelo de algo otorgado por los países poderosos a los demás. Porque, en este nuevo contexto mundializado, la creación de instituciones mundiales exige planteamientos radicalmente nuevos: no desde el poder del más fuerte (como ha sido siempre hasta ahora), sino desde una responsabilidad compartida por todos los pueblos.

Si hay una lección importante derivada de la "batalla de Seattle" es precisamente ésta: el contraste entre una incipiente y limitada toma de conciencia de la gravedad de los problemas mundiales (muchos de los cuales ni siquiera eran competencia de la OMC) por parte de la sociedad civil, y la incapacidad de los gobiernos, a los que la preocupación casi obsesiva por sus propios intereses les impidió ponerse a la altura que el momento exigía. Esto no obsta para reconocer lo sesgado de la sociedad civil que se manifestó en Seattle (sólo ONG del Norte, es decir, de los "satisfechos"), ni lo inadecuado de las formas de expresar la protesta (que más bien contribuyeron a privarla de autoridad). 
2a) Un forta lecimiento de la sociedad civil, incluso a nivel mundial. La sociedad civil está convirtiéndose en un recurso indispensable para salir de la polarización entre el mercado, cuya lógica es a la larga discriminatoria, y el Estado, que por un exceso de confianza en él ha terminado naufragando en la ineficiencia y la corrupción. El protagonismo de la sociedad civil (es decir, de los ciudadanos de forma espontánea y/ o organizada) supone que ya no hay que encerrarse en la alternativa de que lo que no resuelve el mercado hay que encomendarlo al Estado, porque en la sociedad hay capacidad para abordar los problemas, arbitrar soluciones, corregir y complementar las iniciativas del mercado (y su lógica implacable del beneficio) o controlar efectivamente a los poderes públicos (por parte de aquellos que, en último término, le dan legitimidad).

Pero el proceso de reconstrucción y rearticulación de la sociedad civil está siendo lento. Mucho más lento habrá de ser en el nivel mundial, donde es una realidad casi sin precedentes. Pero los medios de comunicación ofrecen aquí una oportunidad nueva para establecer redes y promover actuaciones en que ciudadanos de diferentes países, que se sienten ciudadanos del mundo y actúan como tales, ejerzan presión y control sobre los gobiernos nacionales y sobre los organismos internacionales.

También Seattle debe ser invocado aquí como una experiencia ilustrativa. Como ya decíamos, en aquella ciudad norteamericana se manifestó con fuerza una parte (la más privilegiada, repetimos) de la sociedad civil, en la que va aumentando la conciencia de sus responsabilidades. Y sería lástima que la escasa representatividad de los manifestantes o las formas extremistas que adoptaron ( ¿la única manera de hacerse oír en las actuales circunstancias?) impidieran comprender el significado profundo de lo que muchos despreciaron como una "revuelta de insatisfechos". ¿No significa esta "revuelta" que en adelante no puede ignorarse a la sociedad civil y a sus organizaciones espontáneas en toda iniciativa de organizar un poco este mundo, hasta ahora estructurado desde la fuerza del capital o de las armas?

3a) Una nueva mentalidad crítica y alternativa. Hay que preguntarse también por la savia que alimenta estas propuestas de nuevo sistema de gobierno mundial, estos movimientos sociales y esa articulación de la sociedad civil. Y aquí es obligado mencionar otra vez a la globalización como ideología. Porque en ella va incluida una mentalidad que privilegia la lógica del mercado y aspira a imponerla en todos los ámbitos de la vida humana y social.

La exaltación del mercado, que conlleva la apuesta por la globalización y 
forma parte del discurso neoliberal, supone no sólo la opción por un modelo de organización económica, sino además la adhesión a los valores dominantes en él, que se organizan en torno a la competitividad. No es que neguemos el valor de la competitividad, pero sí somos escépticos frente a ese entusiasmo desmedido por ella. ¿No se oculta tras ese fervor competitivo toda una forma de entender a la persona humana que privilegia en ella lo que tiene precio en el mercado? "Vales lo que vales en el mercado". Es cierto que hay que ser competitivos, pero la obsesión por serlo desde las mismas aulas de la universidad, o incluso antes, ¿no lleva a concebir el mundo como una lucha de todos contra todos, donde domina la hostilidad y siempre está amenazada la supervivencia?

No es fácil proponer aquí una alternativa, pero al menos puede pedirse una cierta lucidez para no conformarse con este modelo que parece imponérsenos desde el mundo de la economía. Porque por este camino la eficacia económica está perdiendo su condición de medio al servicio del bienestar y de la felicidad humana, para convertirse en fin que lo justifica todo.

La propuesta de valores alternativos puede articularse desde una opción decidida por la solidaridad, entendida en contraposición a la competitividad: como la actitud que nos hace vivir a todos como responsables de todos, no como competidores con todos. ¿No habría de ser la solidaridad un contrapunto indispensable para un mundo tan marcado por un sistema de valores en el que la competitividad es la cumbre? Sería prolijo entrar aquí en fórmulas que hagan operativa esta apuesta por la solidaridad. Pero no faltan los ejemplos, aunque su fuerza nos parezca casi ridícula frente al empuje de la competitividad. Una mentalidad crítica, que no quiera limitarse a la denuncia, deberá ser sensible a estas iniciativas emergentes para destacar cómo en ellas despunta un orden de valores nuevo. ¿No están en esa línea las campañas recientes del 0,7\% o de la deuda externa con motivo del Jubileo 2000? ¿O los movimientos de autoorganización de sociedades muy azotadas por la crisis, que han descubierto en iniciativas nacidas por pura necesidad de supervivencia recursos sociales desconocidos?

\section{Conclusión: globalización integradora vs. globalización excluyente}

Este quisiera ser nuestro mensaje final. La globalización es un hecho incuestionable e irreversible. Pero no hay que dejarse llevar sin más de él porque su propia dinámica es excluyente. Es necesario someterlo a control, no 
sólo reducir su alcance sino reconducir sus potencialidades. Se impone, por consiguiente, un esfuerzo por encauzar las fuerzas inmensas de este proceso hacia lo contrario de la exclusión: hacia la integración.

Escierto que por integración se entienden cosas diferentes. Tal como nosotros la conocemos en la Unión Europea, es un elemento esencial para la cohesión de pueblos, regiones y territorios, gracias a unas instituciones con capacidad decisoria tanto en el ámbito político como en el económico. Así entendida la integración es un proyecto articulado y dotado de medios. Integración no es, pues, la mera eliminación de las fronteras para facilitar los movimientos de recursos económicos o de personas, sino el esfuerzo por hacer "mío" lo del "otro" como algo que me afecta y me obliga a obrar en consecuencia.

A escala planetario es difícil concebir la integración en ese nivel, no sólo por la mayor complejidad del conjunto a integrar, sino también por la carencia de instituciones adecuadas. Pero esto no significa que haya que renunciar a todo intento integrador. Se trataría, por lo menos, de arbitrar mecanismos cuyo objetivo sea combatir la exclusión, que es el efecto espontáneo de la globalización incontrolada, o al menos los efectos negativos de ésta. Y cabría promover proyectos que garantizaran un trato preferencial para los amenazados de exclusión. Las negociaciones comerciales en curso serán, una vez más, excelente ocasión para responder por fin a demandas ya antiguas de los países menos desarrollados.

Todo ello exige una sociedad consciente frente a los poderes políticos y económicos, no para anular a éstos, sino para ponerlos al servicio de la humanidad. Exige, más concretamente, una sociedad con conciencia planetaria, con conciencia de humanidad. Y esta conciencia encontrará cauces para reconstruir el mundo de otra manera, desde unos presupuestos y unas instituciones.

Puede que esta conclusión parezca una utopía. Pero no olvidemos que todas las grandes conquistas de la humanidad comenzaron siendo "utopías" y encontraron el rechazo, cuando no el desprecio, de los más acomodados. 